\title{
Application of Through-Flow Calculation to Design and Performance Prediction of Centrifugal Compressor
}

\author{
Y.S. CHOI and S.H. KANG*
}

Department of Mechanical Engineering, Seoul National University, Kwan-ak Ku, Shinrim Dong, Seoul, 151-742, Korea

(Received 15 January 1998; Revised 19 March 1998; In final form 2 April 1998)

\begin{abstract}
A computer code predicting the flows through the centrifugal compressor with the radial vaneless diffuser was developed and applied to investigate the detailed flowfields, i.e., secondary flows and jet-wake type flow pattern in design and off-design conditions. Various parameters such as slip factors, aerodynamic blockages, entropy generation and two-zone modeling which are widely used in design and performance prediction, were discussed.

A control volume method based on a general curvilinear coordinate system was used to solve the time-averaged Navier-Stokes equations and SIMPLER algorithm was used to solve the pressure linked continuity equation. The standard $\mathrm{k}-\varepsilon$ turbulence model was used to obtain the eddy viscosity. Performance of the code was verified using the measured data for the Eckardt impeller.
\end{abstract}

Keywords: Centrifugal compressor, Three-dimensional analysis, $k-\varepsilon$ model, Secondary flows, Jet-wake flow, Performance prediction

\section{INTRODUCTION}

Centrifugal compressors are widely used to achieve high pressure ratios per stage and the system results in compact and lightweight design. The flow through the rotor is complex due to growth of boundary layers and separation on blade surfaces, the formation of secondary flows due to rotation and passage curvature and tip leakage in the impeller passages. Resulting jet-wake formation is associated with high viscous losses and affects the operating range of the rotating impeller and the diffuser downstream. To improve the aerodynamic performance of centrifugal compressors it is necessary to suppress the separation and wake formation maintaining high level of diffusion within the impeller. It is essential to understand the flow structure to achieve these objectives within the passages. A lot of parameters such as slip factors, flow blockages and entropy generation etc., are used in the design and performance prediction process. The main purpose of the present work is to investigate through flows and estimate such parameters with the three-dimensional flow calculation.

*Corresponding author. Tel.: 82-2-880-7113. Fax: 82-2-883-0179. E-mail: kangsh@plaza.snu.ac.kr. 
The flow calculation was carried out using a three-dimensional, finite volume, pressure correction method, with a two-equation $k-\varepsilon$ turbulence model, for the solution of the time-averaged Navier-Stokes equations in a rotating frame of reference. The discretized equations for the physical covariant velocity components were obtained by an algebraic manipulation of the discretized equations for the Cartesian velocity components.

The performance of the code was verified using the measured data for the Eckardt backswept impeller. Eckardt (1980) performed detailed measurements, using a Laser-2-Focus velocimeter, in the high-speed backswept impeller.

\section{GOVERNING EQUATIONS}

The conservation equations for mass, momentum and energy which govern the steady, viscous and compressible flow, expressed in a Cartesian coordinate system in a rotating frame of reference, are given as follows:

Mass,

$$
\frac{\partial}{\partial x_{i}}\left(\rho u_{i}\right)=0 ;
$$

Momentum,

$$
\begin{aligned}
& \frac{\partial}{\partial x_{j}}\left(\rho u_{i} u_{j}\right)=-\frac{\partial p}{\partial x_{i}} \\
& \quad+\frac{\partial}{\partial x_{j}}\left[\mu\left(\frac{\partial u_{i}}{\partial x_{j}}+\frac{\partial u_{j}}{\partial x_{i}}-\frac{2}{3} \frac{\partial u_{k}}{\partial x_{k}} \delta_{i j}\right)-\overline{\rho u_{i}^{\prime} u_{j}^{\prime}}\right] \\
& \quad-2 \rho \varepsilon_{i j k} \Omega_{j} u_{k}-\rho\left(\Omega_{m} x_{m} \Omega_{i}-\Omega_{n} \Omega_{n} x_{i}\right) ;
\end{aligned}
$$

Energy,

$$
\begin{aligned}
& \frac{\partial}{\partial x_{j}}\left(\rho u_{j} H_{R}\right)=\frac{\partial}{\partial x_{j}}\left(-q_{j}-\rho \overline{u_{j}^{\prime} h^{\prime}}\right) \\
& \quad+\frac{\partial}{\partial x_{j}}\left[u_{i}\left\{\mu\left(\frac{\partial u_{i}}{\partial x_{j}}+\frac{\partial u_{j}}{\partial x_{i}}-\frac{2}{3} \frac{\partial u_{k}}{\partial x_{k}} \delta_{i j}\right)-\overline{\rho u_{i}^{\prime} u_{j}^{\prime}}\right\}\right]
\end{aligned}
$$

where $H_{R}$ is rothalpy, $\rho$ the density, $\Omega$ the rotational speed, and $\varepsilon_{i j k}$ the alternating tensor.
The following additional transport equations are solved to obtain $k$ and $\varepsilon$ for turbulence closure:

$$
\begin{aligned}
\frac{\partial}{\partial x_{j}}\left(\rho u_{j} k\right)= & \frac{\partial}{\partial x_{j}}\left[\left(\mu+\frac{\mu_{t}}{\sigma_{k}}\right) \frac{\partial k}{\partial x_{j}}\right] \\
& +\mu_{t} \frac{\partial u_{j}}{\partial x_{i}}\left(\frac{\partial u_{i}}{\partial x_{j}}+\frac{\partial u_{j}}{\partial x_{i}}\right)-\rho \varepsilon, \\
\frac{\partial}{\partial x_{j}}\left(\rho u_{j} \varepsilon\right)= & \frac{\partial}{\partial x_{j}}\left[\left(\mu+\frac{\mu_{t}}{\sigma_{\varepsilon}}\right) \frac{\partial \varepsilon}{\partial x_{j}}\right] \\
+ & C_{1} \mu_{t} \frac{\varepsilon}{k} \frac{\partial u_{j}}{\partial x_{i}}\left(\frac{\partial u_{i}}{\partial x_{j}}+\frac{\partial u_{j}}{\partial x_{i}}\right)-C_{2} \frac{\rho \varepsilon^{2}}{k},
\end{aligned}
$$

where

$$
\mu_{t}=C_{\mu} \rho \frac{k^{2}}{\varepsilon}
$$

and the model constants are summarized as follows: $C_{\mu}=0.09, C_{1}=1.44, C_{2}=1.92, \sigma_{k}=1.0$, $\sigma_{\varepsilon}=1.0$.

\section{METHOD OF CALCULATION}

Calculations are carried out in a non-orthogonal curvilinear coordinate $(\xi, \eta, \zeta)$ system. The discretized equations are obtained using a finite volume method (Karki and Patankar, 1988). A staggered grid arrangement is used. The scalar variables are located at the geometric center of a control volume, while the physical covariant velocity components $u_{\xi}, u_{\eta}$ and $u_{\zeta}$ are located on the mid-points of the control faces. A power law differencing scheme is employed to evaluate the combined convection-diffusion fluxes on the control surfaces. The physical covariant velocity components, which are directed along the coordinate lines, are used as the dependent variables in the momentum equations. The discretization is performed using Cartesian velocity components in a locally fixed coordinate system (Karki and Patankar, 1988). A pressure correction equation is obtained by the SIMPLE algorithm. The velocity components from the momentum equations are corrected to satisfy 
the continuity equation. However, the pressures are obtained by the SIMPLER (Patankar, 1980) scheme using the full momentum equations. Density at a control volume face is always upwind-biased. This allows the computation of transonic and supersonic flows.

A cyclic TDMA (Ramamurti et al., 1988) is used to obtain numerical solution of the discretized equation. Convergence is assumed when the maximum relative error of the pressure field is less than $10^{-4}$

\section{RESULTS AND DISCUSSION}

The data published by Eckardt (1980) were chosen to validate the present code. The test impeller is a typical high-speed backswept impeller shown in Fig. 1. Eckardt (1980) performed measurement for the performance, pressure distribution along the shroud and the velocity field within the impeller. The measured data have been widely used to validate computational codes and also quoted in describing the flow characteristics along the impeller.

The results of the present calculation were compared with the measured data and the flow characteristics were also discussed in comparison with the given data. The geometry data were obtained from Schuster and Schmidt-Eisenlohr (1980). The impeller has 20 blades and the main camber line has an elliptic shape (in cylindrical sections). The backward curvature commences at $R / R_{2}=0.8$ and terminates at the blade exit with a backsweep angle of $30^{\circ}$. The compressor operates at a rotational speed of $14,000 \mathrm{rpm}$ and the design mass flow rate is $4.54 \mathrm{~kg} / \mathrm{s}$. The inlet total pressure is $101.3 \mathrm{kPa}$ and the total temperature is $288.1 \mathrm{~K}$. Figure 1 shows the backswept impeller along with the meridional measurement planes.

\section{Grid Test and Boundary Conditions}

The computation was carried out using an H-type grid system. Three different grid sets consisting of
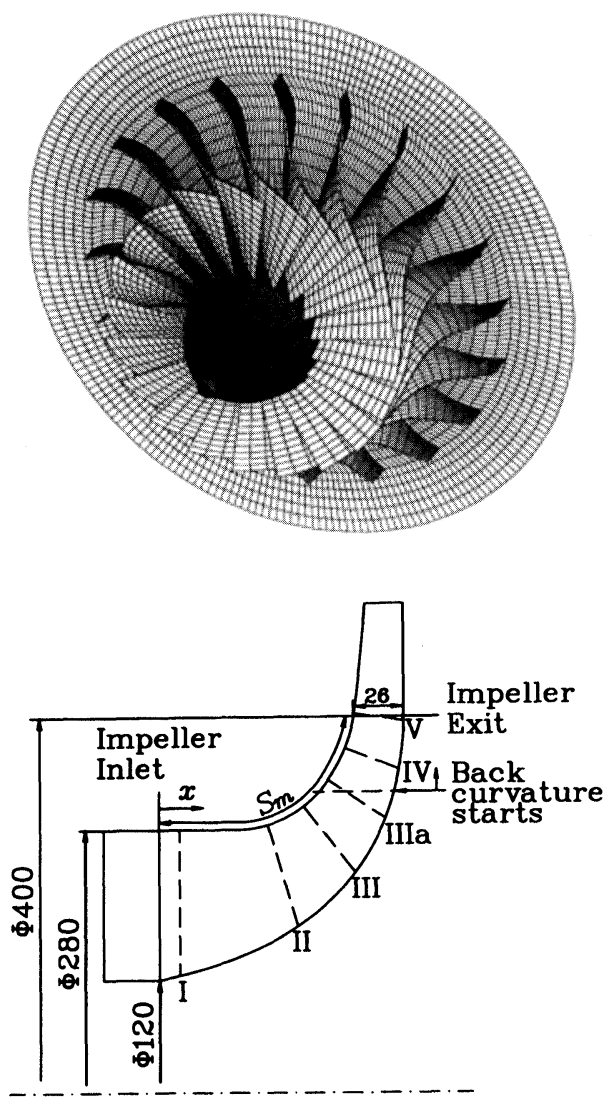

FIGURE 1 Configuration of Eckardt impeller "A" and measurement planes.

$52 \times 26 \times 26,72 \times 26 \times 26,80 \times 26 \times 26$ (in streamwise, blade-to-blade and hub-to-shroud space respectively) points were tested for the design flow rate. The results using the $72 \times 26 \times 26$ grid was considered to provide grid independent solutions and was used for the calculation for the off-design conditions. The blade thickness distributions were obtained from the figures in Schuster (1980). The test impeller is an unshrouded one with a tip clearance. To eliminate the uncertainty of the simplified tip clearance geometry on the flow fields the geometry was not included in the present calculations.

The flow domain is defined by blade-to-blade and hub-to-shroud space. At the inlet boundary upstream of the impeller, the flow is assumed 
uniform and axial. The values of total pressure and total temperature are specified there. The turbulent kinetic energy is uniformly distributed with intensity of $10 \%$. The absolute velocities on the stationary shroud and diffuser walls downstream are equal to zero and the relative velocity on the blades and hub is zero. A wall function is used for the boundary condition of the turbulence model. An adiabatic condition is imposed on the solid walls. The periodic boundary condition is used implicitly upstream and downstream of the impeller. The present code was implemented on a DEC 3000/M400 workstation. Acceptable convergence was generally attained after 1500 iterations, and each iteration required $85 \mathrm{~s}$ CPU time.

\section{Overall Performance and Pressure Distribution}

The overall performance parameters, i.e. total pressure ratios, total temperature ratios and isentropic efficiency, downstream of the impeller exit (position 03 defined by Eckardt (1980) at the radial location of $R / R_{2}=1.075$ ) are shown in Fig. 2. The measured data were obtained by space averaging the data in Fig. 6 of Eckardt (1980). The rotor efficiency was based on the total pressure traverses at $R / R_{2}=1.075$ and the values of temperature were measured at $R / R_{2}=1.687$ (consequently they include the jet-wake mixing losses in the vaneless diffuser entry region). Two results of performance prediction are shown. The first type of averages were obtained by mass averaging the values circumferentially (blade-to-blade) and then spatially averaging them spanwise (hub-to-shroud). The second one was obtained by mass averaging them over the whole plane. Predicted performance characteristics show good agreement with measurements. The predicted values of total pressure rise are $2 \%$ lower than the measured values at the near stall and design conditions, and slightly higher at the near choke condition. The predicted temperature rise curve is consistently $1-2 \%(1.3 \mathrm{~K}$ at the design point) lower than the measured data. The efficiency was best estimated at the stall and the design flow rates and slightly overpredicted at
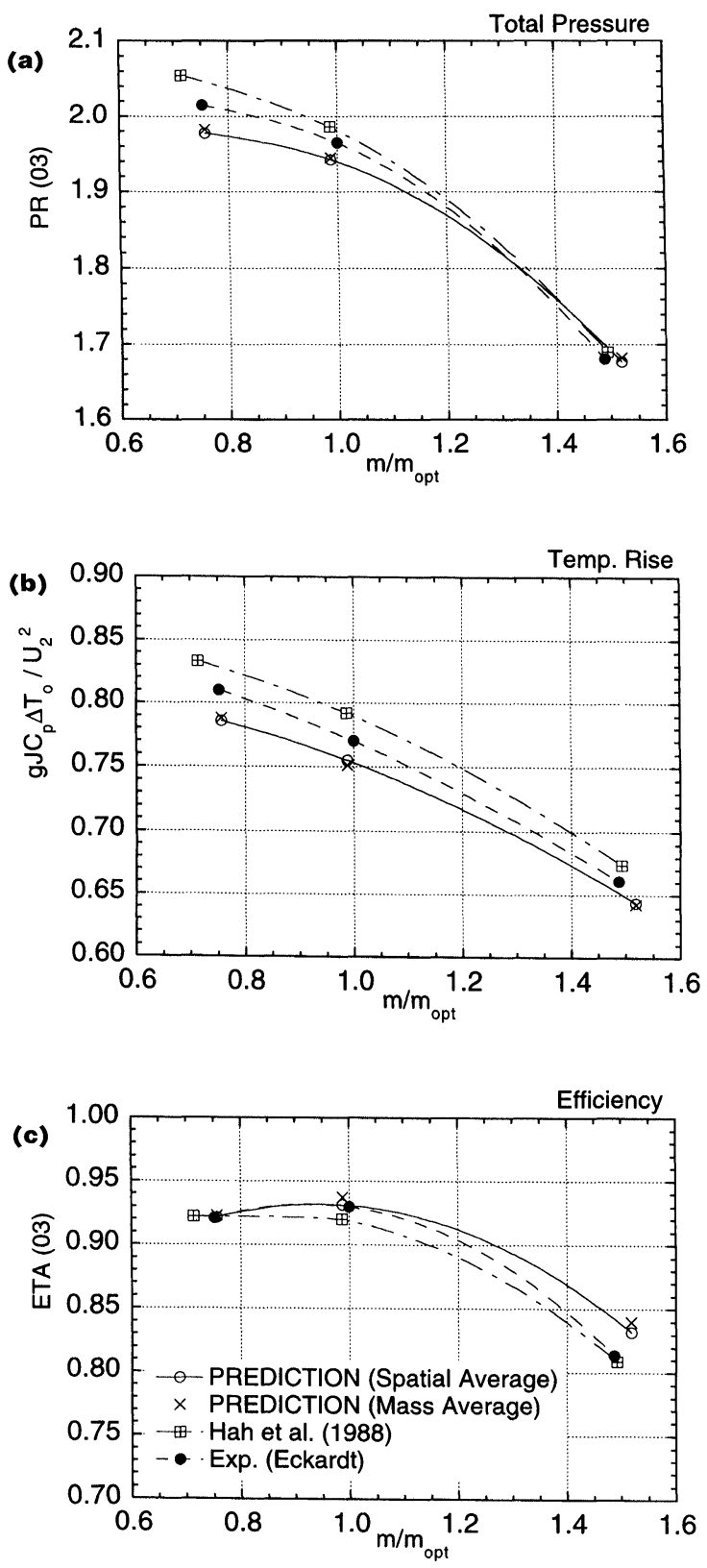

FIGURE 2 Calculated and measured performance parameters: (a) pressure ratio, (b) temperature rise, (c) efficiency.

the choke condition. The difference may be due to the uncertainty in measurements, neglected tip clearance, turbulence modeling, various assumptions involved in the description of the geometry and the boundary conditions. 
The circumferentially averaged static pressure distributions calculated on the shroud are compared with the time-mean measurements and other calculations at the design and near choke flow rates in Fig. 3(a) and (b). Quasi-three-dimensional calculation with an empirical loss model by Schuster et al. (1980) overpredicts the pressure distribution over the inducer region. The predicted values of the present viscous flow calculation and Hah et al. (1988) are in good accordance with the measured values. Figure 3(c) compares the shroud static pressure distribution at three operating conditions. The pressure continuously increases through the impeller at the design and near stall conditions. However, at the near choke flow rate, the flow accelerates in the inducer region, especially along the suction side over the shroud. The pressure decreases over the inducer, then increases downstream. The performance and variation of static pressure is successfully predicted in the present calculation.

\section{Mean Velocity Field}

The calculated through-flow development of the backswept impeller is presented in Fig. 4 for three flow rates. The measured data at the design flow rate are also shown for direct comparison. The plots show the meridional component of the absolute velocity, referred to the impeller tip speed. The planes I and II are in the axial inducer region, the planes III and IIIa are in the axial to radial region and the planes IV and $\mathrm{V}$ are close to the impeller exit. In the axial inducer region, the velocity distributions develop regularly at the design and near the choke flow rates. However, the flow separation near shroud/suction side at the plane I and shroud/pressure side at the plane II were shown at the near stall flow rate.

In the axial to radial region, the velocity distributions at the near stall flow rate show that the lowmomentum fluid region is spread wide over the shroud region at the plane III and moves to the shroud/suction region at the plane IV. Considering the design flow rate, the flow distortion starts near
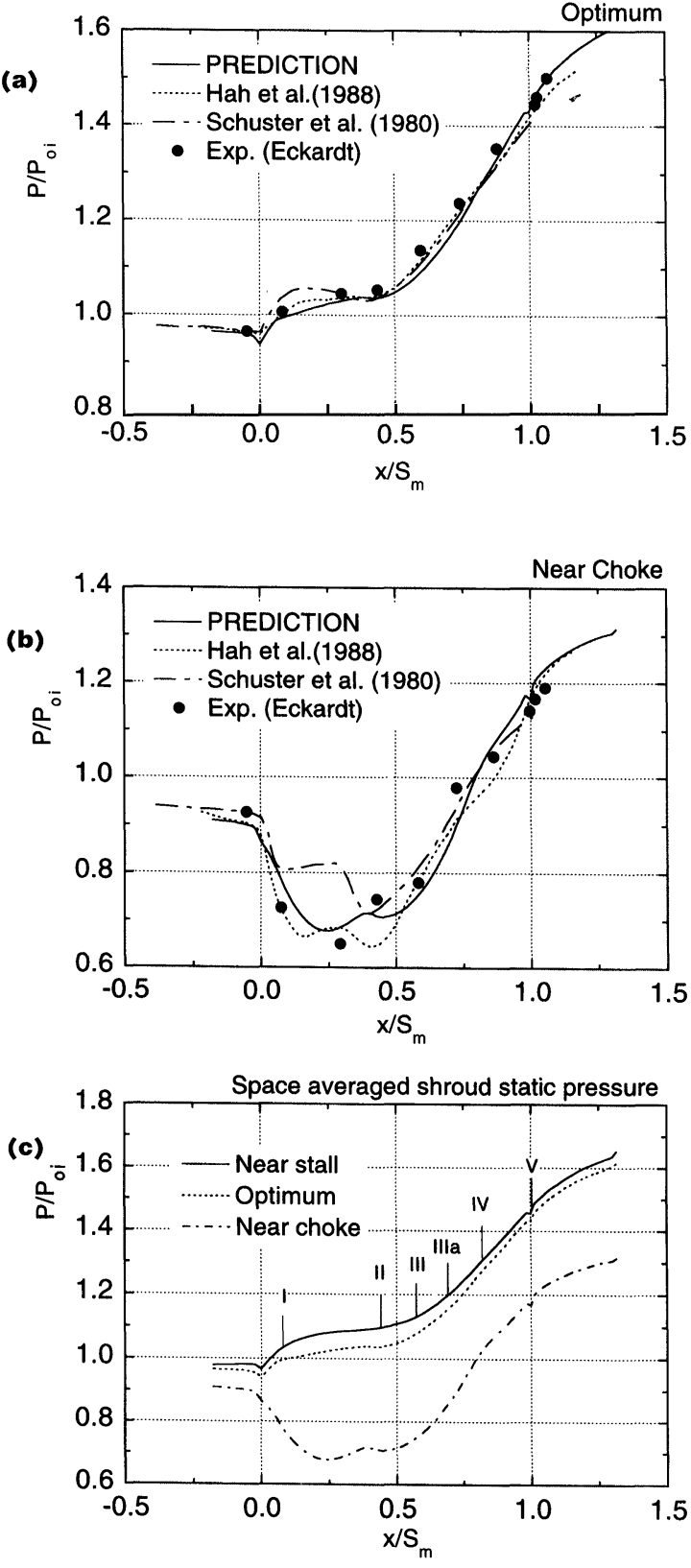

FIGURE 3 Distributions of static pressure over the shroud for (a) design and (b) near choke flow rates; (c) variation of predicted static pressure distributions for three flow rates.

the shroud wall at the plane III, which is not shown in measurement, and as the blade-to-blade loading increases the low-energetic fluid region is seen near the shroud wall at the plane IIIa. No particular flow 


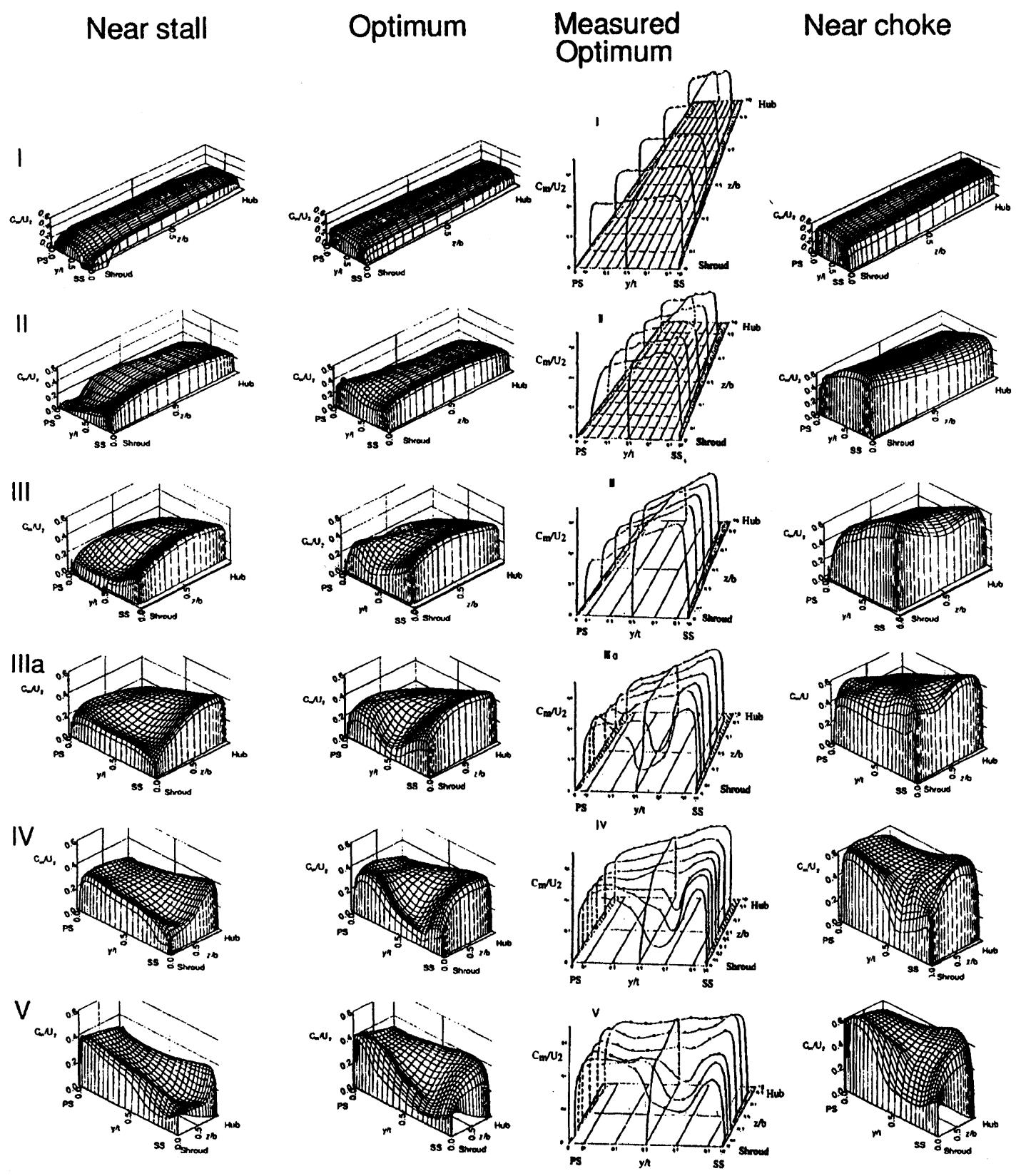

FIGURE 4 Comparison of flow development at three different flow rates.

deceleration is shown at the near choke flow rate but the flow is slightly distorted near the shroud/ suction side at the plane IIIa.

Near the impeller exit region, the movement of a low-momentum wake region to a suction side continued at the plane IV for the near stall flow rate. The final location of the wake region is near the suction side of the impeller at the plane V. At the design flow rate, the wake region moves to the shroud/suction side due to the secondary flow and 
this wake flow pattern is also observed in the measurement data. The pattern of the lowmomentum wake generation is not so clearly seen at the near choke flow rate as at the design condition but the wake region is also located in the shroud/suction side at the plane V.

Figure 5 shows the velocity distributions at the measurement planes $\mathrm{I}-\mathrm{V}$ on the blade-to-blade surfaces near the shroud, at the mid-channel position and near the hub for the design flow rate. The present viscous flow calculation and quasithree-dimensional calculation results show excellent agreement at the mid-channel position and near the hub surfaces through all the planes. However, considering the near shroud surface, the present calculation simulates the wake formation very well from the plane IIIa to the plane $\mathrm{V}$ but the quasi-three-dimensional method fails. The low momentum wake region already starts at the plane III for the present calculation, which is guessed to be between the plane III and IIIa in the measurement, and the wake depth is slightly underpredicted at the planes IV and V.

The velocity distributions at the near choke flow rate are compared with experimental data and the quasi-three-dimensional calculation in Fig. 6. Both methods predict the velocity distribution very well in the potential core region. The wake flow pattern is not simulated by the quasi-three-dimensional method near the shroud region after flow separation. The present calculation results do not simulate the incipience of a separation zone near the shroud suction side of the blade at the planes III and IIIa. However, the complex jet-wake structure is predicted very well at the planes IV and V.

\section{Secondary Flow and Jet-Wake Formation}

Simulation of the through flow shows the mechanism how the rotation and curvature contribute to the formation and movement of the jet-wake flow pattern within the impeller. Streamwise vorticities and secondary flows develop when a shear or boundary layer is subjected to centrifugal and Coriolis forces. The relative magnitude of these two contributions is defined by the Rossby number $\left(R_{0}=W / \omega R_{\mathrm{n}}\right)$. The blade curvature induces the secondary flow in the inducer region and the shroud and hub curvature induce secondary flow in the axial to radial bend. Rotation induces the secondary flow in the radial section of the impeller downstream. For the backswept impeller, the Coriolis-induced secondary flow is usually opposed by the secondary flow generated by the backswept blade curvature.

The secondary flow is defined as the departure of the local relative velocity vector from the local streamwise direction. If the ideal flow follows the local blade direction in the B-B planes and local streamwise grid direction in the $\mathrm{H}-\mathrm{S}$ plane, the components of secondary velocity vectors are zero. According to the above definition, the velocity vectors of the secondary flow at the measurement planes IV and $\mathrm{V}$ are shown for three operating flow rates in Fig. 7. The contours in Fig. 7 are the predicted meridional velocity components $\left(C_{\mathrm{m}} / U_{2}\right)$. The migration and accumulation of low momentum fluid in the boundary layer and the wake can be illustrated by the secondary flow motion through the impeller. To describe the secondary flow development and the wake formation, it is useful to define dimensionless rotary stagnation pressure as

$$
P^{*}=\frac{p^{*}-p_{\min }^{*}}{p_{\max }^{*}-p_{\min }^{*}},
$$

where $p^{*}=p+\frac{1}{2} \rho W^{2}-\frac{1}{2} \rho \omega^{2} r^{2}$ is the rotary stagnation pressure. It conserves along a streamline in steady, inviscid, incompressible flow through the rotating impeller. The distributions of dimensionless rotary stagnation pressure at the planes IV and $\mathrm{V}$ are shown in Fig. 8. At the near stall flow rate the prevailing anti-clockwise passage vortex is located at the suction side. When the flow rate is low, the Rossby number is small and the wake flow appears on the suction surface. The low $P^{*}$ fluid, which is near the shroud/suction side at the plane IV, moves to the suction side of the impeller exit at the plane $\mathrm{V}$. Inoue and Cumpsty (1984) reported that as the 

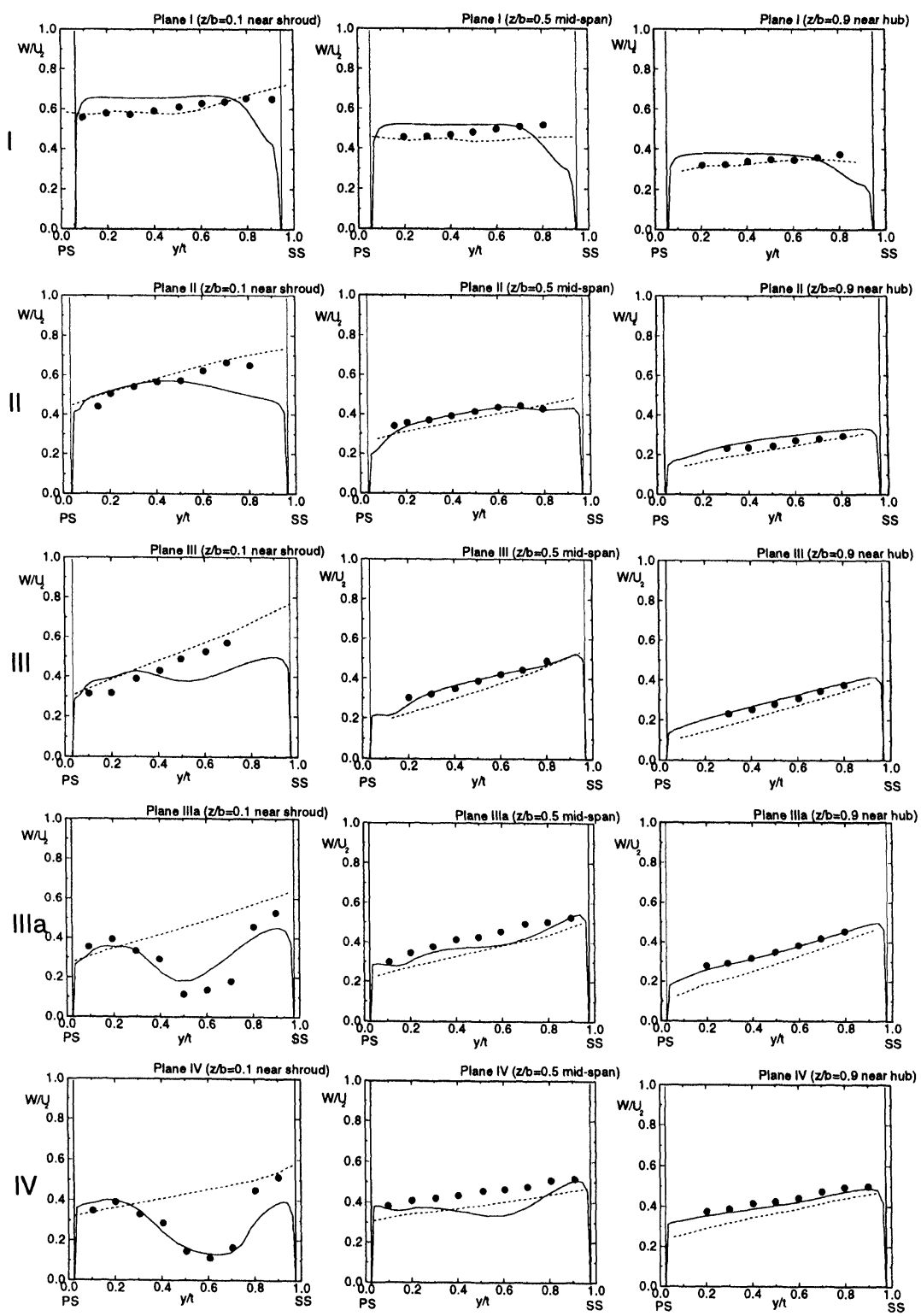

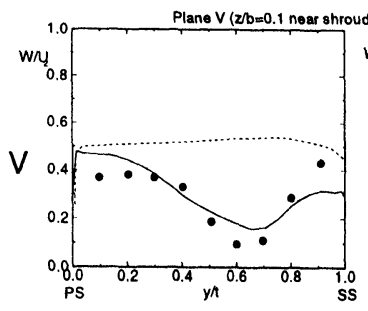

a)

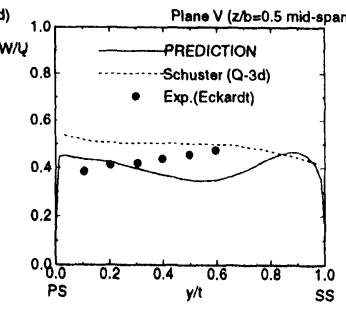

b)

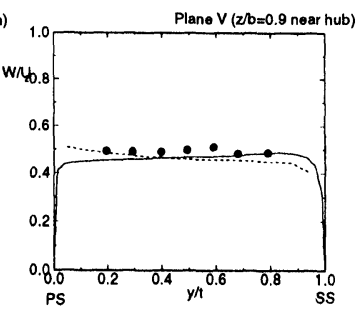

c)

FIGURE 5 Blade-to-blade relative velocity distributions at the design flow rates: (a) near shroud, (b) mid-span, and (c) near hub. 

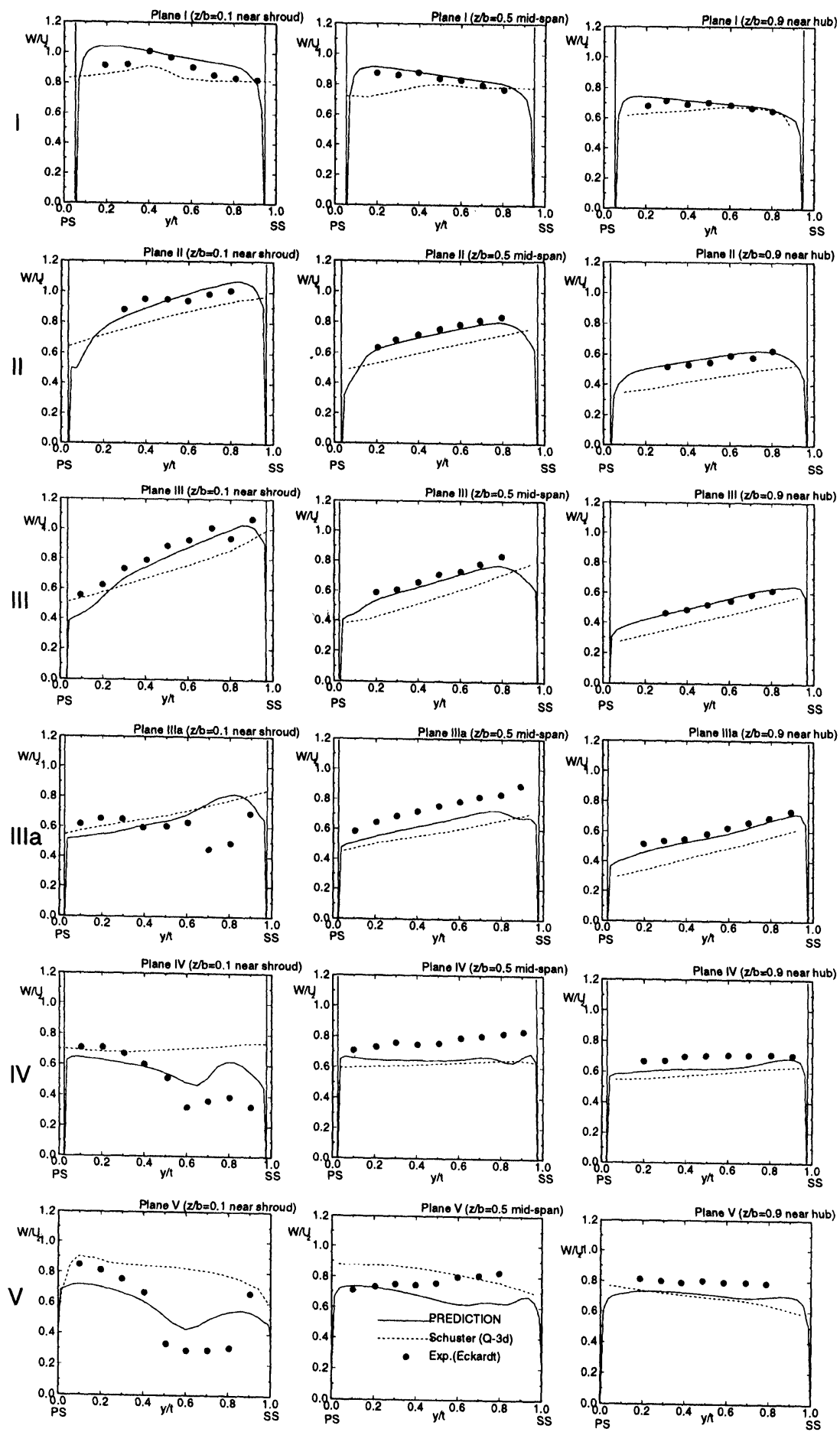

a)

b)

c)

FIGURE 6 Blade-to-blade relative velocity distributions at near the choke flow rates: (a) near shroud, (b) mid-span, and (c) near hub. 


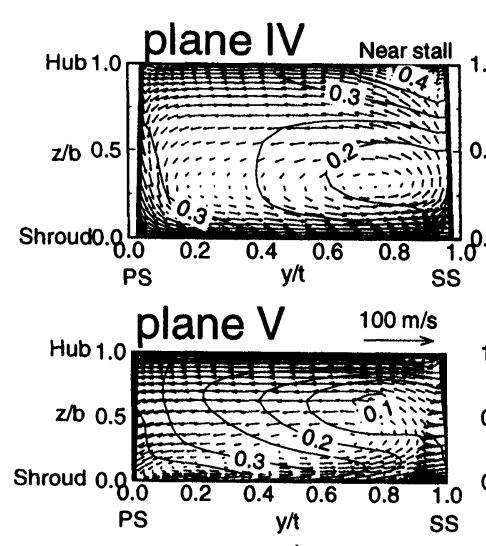

a)

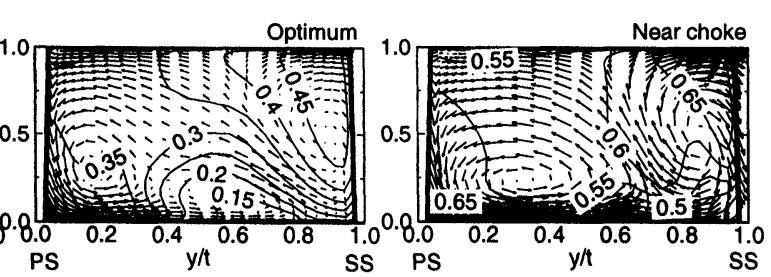

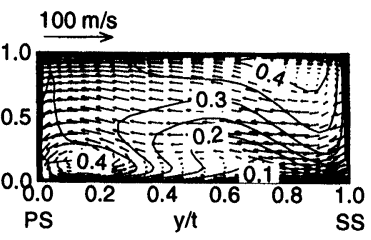

b)

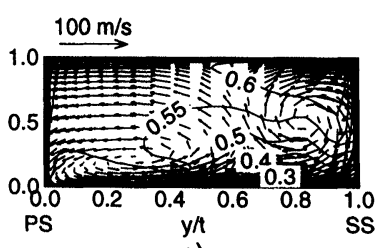

c)

FIGURE 7 Developments of the secondary flow velocity vectors and the meridional velocity contours near the impeller exit: (a) near stall, (b) design, and (c) near choke flow rates.

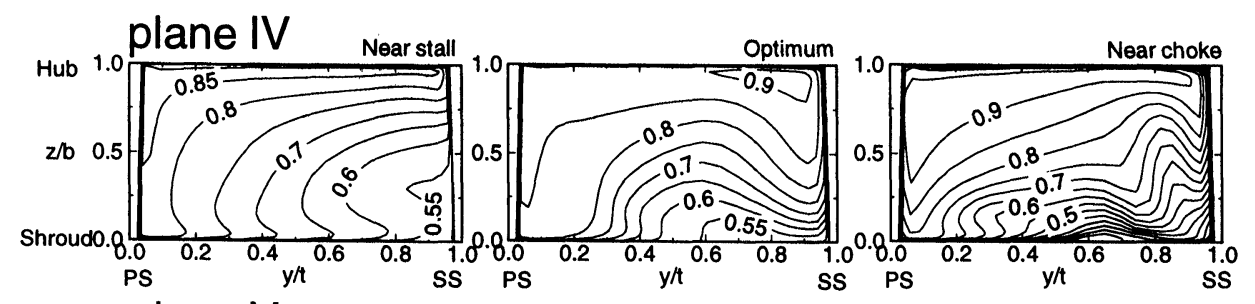

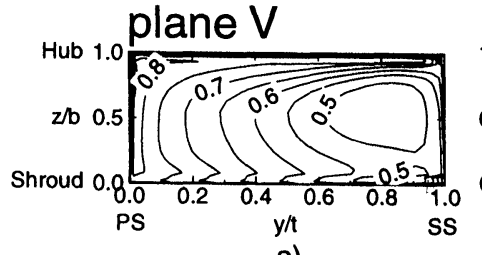

a)

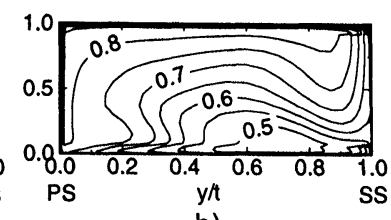

b)

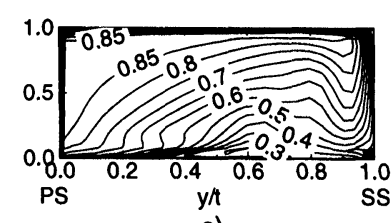

c)

FIGURE 8 Dimensionless rotary stagnation pressure contours near the impeller exit: (a) near stall, (b) design, and (c) near choke flow rates.

Rossby number becomes small (in case of $R_{0}=0.48$ ), the strong Coriolis force moves the stable location of the wake from the shroud to the suction surface and inertia of the strong secondary flow pushes the wake further around the hub side. In the present predictions, the Rossby numbers at the plane IV are 0.66 for the near stall, 0.84 for the optimum and 1.48 for the near choke flow rates, respectively.

For the design flow rate, migration of vortex along the shroud to the suction side is enhanced by the Coriolis forces due to the rotation at the plane IV. However, the secondary motion over the shroud is less than that of the radial impeller due to the blade backswept curvature. The low $P^{*}$ fluid from two secondary flows, i.e. over the suctionshroud surfaces, collides in the shroud/suction side corner and makes the wake region. The final location of the wake locates at the shroud/suction corner at the plane $\mathrm{V}$.

For the near choke flow rate, the Rossby number is large and the secondary flow due to Coriolis force is rather small, so that the vortex pattern near the suction side plays a dominant role compared to the stall and design flow rates. The low $P^{*}$ fluid collides over the shroud $(y / t=0.6-0.7)$ at the plane IV and 
the wake region locates at the same position. As the flow rate increases, the flow inertia becomes large. The increasing inertia of high flow rates tends to maintain the flow direction, so the secondary flow pattern between the planes IV and V becomes more similar as the flow rate increases.

\section{Slip Factor}

The slip factor is a piece of information important to the compressor designer, of which accurate prediction enables the energy transfer between the impeller and fluid to be estimated. Many models have been suggested in the past as a function of blade numbers, flow coefficients, blade angles, etc. The flow pattern at the impeller exit is quite complex due to the development of the secondary flow through the impeller, so that the slip or deviation angle distributions may also be difficult to obtain in the experiment.

Figure 9 shows the variation of the slip factor with the flow coefficient. Two averages, i.e. space and mass averages at the impeller exit, were performed. Estimated values obtained in the present calculation are compared with Eckardt's experimental results. The measured values were obtained by mass averaging the total temperature rise between the inlet and $R / R_{2}=1.687$. According to Wiesner (1967) correlation of slip factor, which is widely used in design and performance prediction

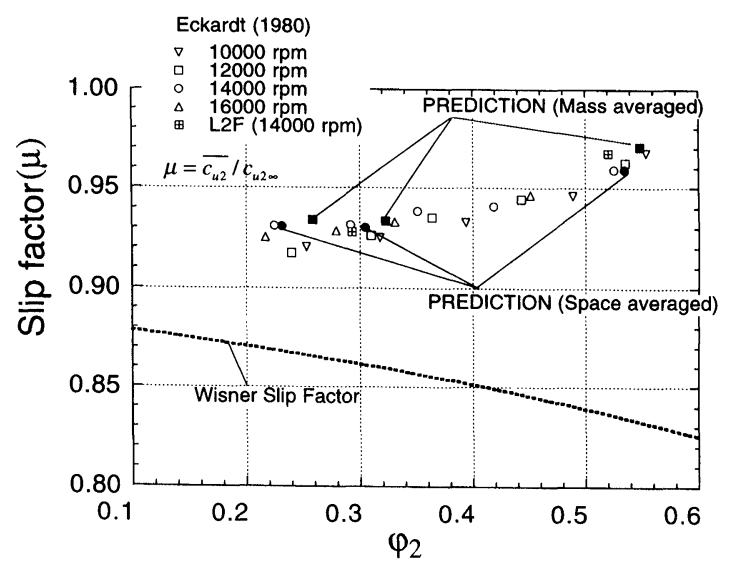

FIGURE 9 Variation of slip factor with flow coefficient. programs, the slip factor decreases with the flow rate. However, the measured and calculated values, which are within an experimental error band, show completely different tendency. Eckardt (1980) explained this aspect as inertia effect, i.e. the S-shaped blade design of impeller, which guides the flow nearly to the radial direction until the backsweep starts downstream between the planes IIIa and IV. Simulation describes the three-dimensional flow structure near the exit of the impeller. As shown in Fig. 7, the increased inertia of a high flow rate keeps the flow to maintain the strength of the secondary flow up to the impeller exit. Therefore, the effects of the backsweep on the flow at the high flow rate become small. The deviation angle reduces at the impeller exit and the slip factor increases with the flow rate.

\section{Blockage Factor and Entropy Generation}

An aerodynamic blockage is usually defined based on the displacement thickness of the boundary layer in the external flows. However, it is difficult to define the boundary layer thickness on the impeller because of the non-uniformity of the flow. Zangeneh (1993) defined the extent of the flow non-uniformity in the ratio of the area (pitchwise) averaged meridional velocity to the mass-averaged meridional velocity. The aerodynamic blockage distributions in the meridional plane and the blockage development through the impeller for Eckardt (1980) impeller are shown in Fig. 10.

The blockage is mainly generated near the shroud from the axial to radial bend at the design flow rate. The blockage grows from the plane I to IIIa due to the blade to blade velocity difference, i.e. the blade loading. After the plane IIIa the blade loading reduces and the non-uniformity of the jet-wake flow increases, so that the blockage remains nearly constant down to the impeller exit. The jet-wake flow pattern mixes out in the vaneless diffuser region downstream of impeller exit at plane VI $\left(R / R_{2}=1.077\right)$ and the blockage decreases.

For the near stall flow rate, the blockage becomes large at the impeller inlet, especially over the shroud 

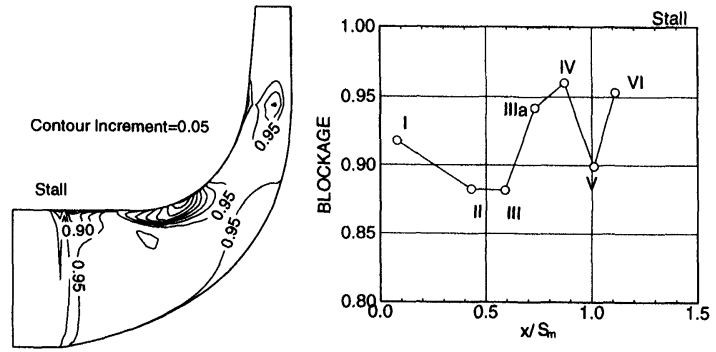

a)
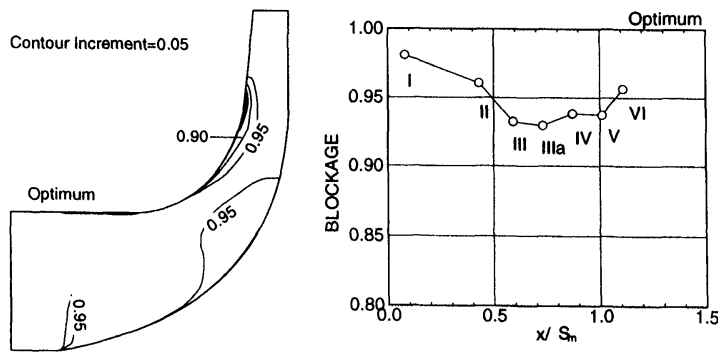

b)
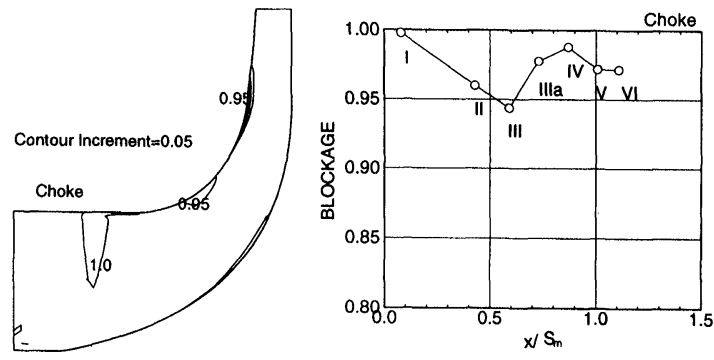

c)

FIGURE 10 Aerodynamic blockage distributions and mass-averaged values at measurements plane: (a) near stall, (b) design, and (c) near choke flow rates.

wall due to the leading edge separation. The shroud blockage region is wider than that for the design flow rate. After the plane III, the blockage decreases over the plane IV according to the recovery of the separation region and increases again at the impeller exit (plane V). The flow for the near choke flow rate is quite stable and the blockage distribution is small everywhere except the small region near the shroud in the axial to radial bend. The mass-averaged blockage increment from the plane I to III depends on the blade loading.
The loss mechanism aspect is strongly threedimensional. One of the important and interesting parameters related to the amount of the loss is the entropy generation. The gradient of an entropy is also used as the source of vorticity and plays an important role in describing the loss mechanisms through the impeller.

The mass-averaged entropy distributions on the meridional plane and the development through the impeller are shown in Fig. 11. The variation of the entropy generation rate is quite similar to that of the blockage. The values of the entropy for the near stall flow rate are large at the plane I due to
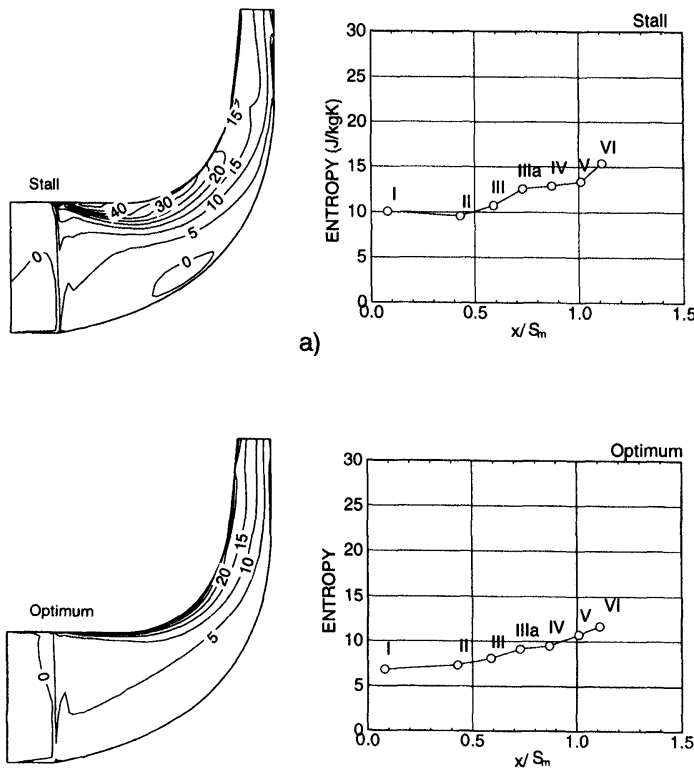

b)
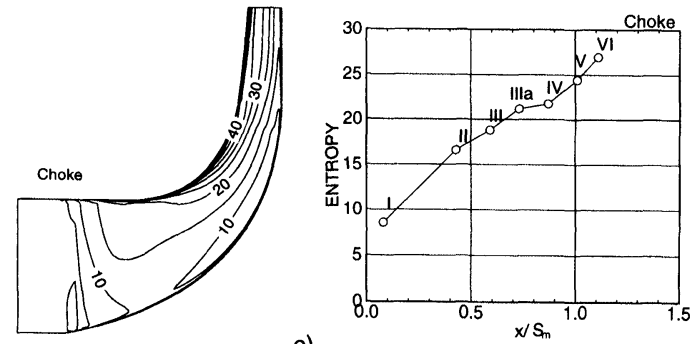

FIGURE 11 Entropy generation distributions and massaveraged values at measurements plane: (a) near stall, (b) design, and (c) near choke flow rates. 
the inlet shroud separation. For the design flow rate the entropy gradually increases from the inlet to the exit and are quite stratified from the hub to the shroud at the impeller exit. For the high flow rate the entropy generation from the plane I to II is definitely higher than for the other flow rate due to the rapid change of loading. The mass-averaged value of the entropy at the impeller exit shows the highest value for the near choke flow rate, which indicates the lowest value of efficiency shown in Fig. 2.

\section{Review of Jet-Wake Model}

The design and performance prediction method with the jet-wake model was proposed by Japikse (1985). The basic idea of the model is to divide the impeller exit flow into jet and wake zones. The assumptions of the model are as follows:

(a) The flow in the jet zone is isentropic;

(b) The flow in the wake zone contains all nonisentropic losses and it leaves the impeller congruent with the blading;

(c) The mass rate fraction of the wake is about $15-25 \%$.

Rohne and Banzhaf (1991) modified the classical jet-wake model based on the measured data.

(a) The jet, although it contains lower losses than the wake, is not isentropic and must be corrected with polytropic efficiency;

(b) The flow in the wake zone is not congruent with the blading and must be applied with

$$
C_{u 2 \mathrm{w}}=F_{u \mathrm{w}} * C_{u 2 \mathrm{~J},}
$$

where $F_{u \mathrm{w}}$ is the circumferential velocity factor for the wake zone.

The original jet-wake theory is based on the conceptual two-zone model (primary and secondary zones). The boundary of the two regimes does not physically exist; the model indicates only that there is an isentropic core flow and that all the non-isentropy of the flow concentrates in the secondary flow regime. However, Rohne and
Banzhaf (1991) defined the wake zone where the local value of the meridional component of velocity is less than $90 \%\left(D F_{\mathrm{w}}=0.9\right)$ of the global mean value. Therefore the properties in the jet and wake zones in the two models are different from each other. The capability of predicting the mixed-out conditions and the parameters in the two models were investigated using predicted values in the present calculation.

The distributions of the entropy at the impeller exit for the three flow rates are shown in Fig. 12. This calculation shows that only the small region of the isentropic core could be found at the impeller exit. A relatively high entropy region (wake region) resides near the suction side for the near stall flow rate and over the shroud/suction corner for the design and choke flow rates. The calculation verifies the first assumption by Rohne and Banzhaf (1991).

Figure 13 shows the velocity triangles at the design flow rate in the impeller exit. The velocity components with two models were obtained using the secondary mass fraction $(\varepsilon=0.135)$ and area fraction $(\chi=0.367)$. The solid lines were obtained from the present calculation for $D F_{\mathrm{w}}=0.9$. The values of the secondary mass and area fraction from the present three-dimensional flow prediction are 0.191 and 0.290 respectively. Note that the mixedout velocity vectors are in good agreement with the values from two models. However, there appear small differences in the calculated total conditions at the impeller exit (see Table I). When the predicted values of total temperature and total pressure at the impeller exit in the present three-dimensional calculation are used, the mass fraction and slip factor can be obtained using two models $(0.564$ for the original model and 0.16 for Rohne and Banzhaf (1991) model). Rohne's model with $F_{u \mathrm{w}}=1.1$ shows the best prediction of the wake absolute tangential velocity component with that of the three-dimensional calculation. Figure 14 shows that both models unusually over-predict the mass fraction in comparison with $0.15-0.25$ for the original jetwake model and 0.13-0.14 for Rohne and Banzhaf (1991) model. 


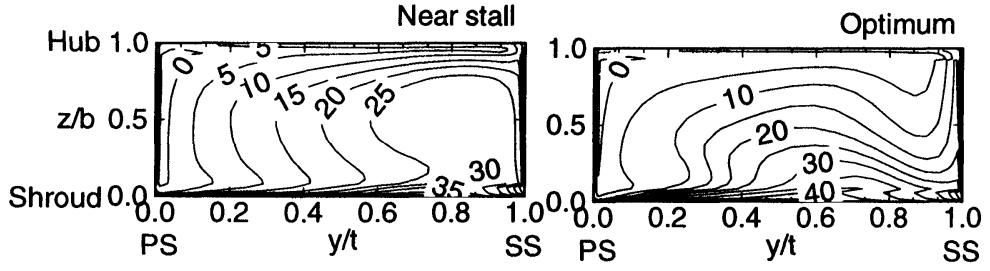

a) b)

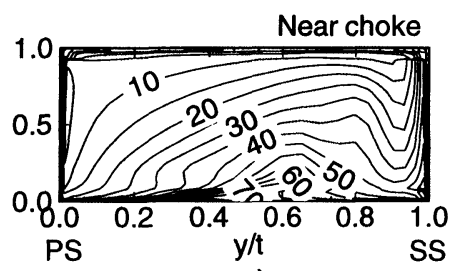

c)

FIGURE 12 Entropy distributions at impeller exit: (a) near stall, (b) design, and (c) near choke flow rates.

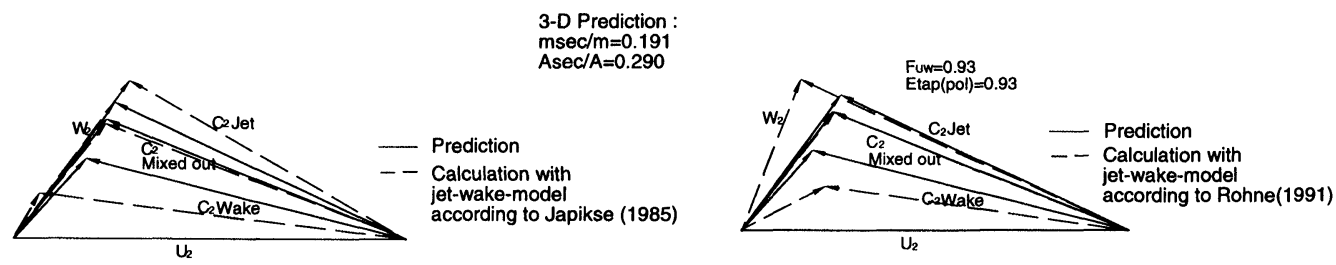

FIGURE 13 Comparison of jet-wake and mixed-out velocity vectors (with proposed input wake mass and area fraction) (a) jet-wake model from Japikse, and (b) jet-wake model from Rohne.

TABLE I Comparison of exit total conditions of two kinds of jet-wake theories using proposed parameters

\begin{tabular}{lccccc}
\hline Model & Guessed & Guessed & Predicted & Predicted & $F_{u \mathrm{w}}$ \\
& $m_{\mathrm{w}} / m$ & $A_{\mathrm{w}} / A$ & $P_{02 \mathrm{~m}}(\mathrm{kPa})$ & $T_{02 \mathrm{~m}}(\mathrm{~K})$ & \\
\hline Classical jet-wake theory & 0.135 & 0.367 & 201.3 & 351.1 & - \\
Rohne's jet-wake theory & 0.135 & 0.367 & 199.4 & 359.4 & 0.93 \\
Three-dimensional calculation & $0.191^{*}$ & $0.290^{*}$ & 198.0 & 353.4 & - \\
\hline
\end{tabular}

* Values are obtained using $D F_{\mathrm{w}}=0.9$.
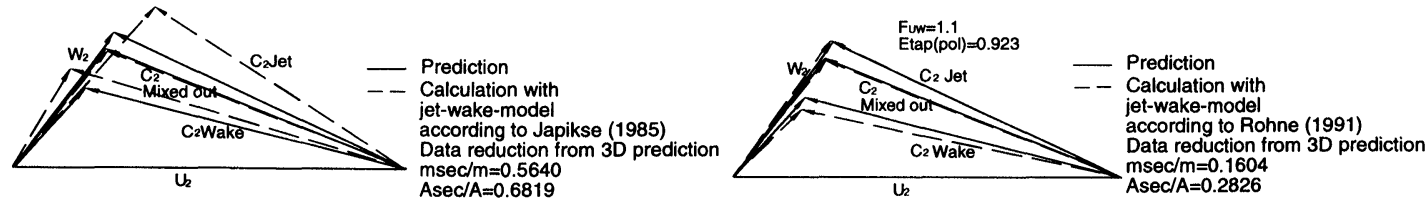

FIGURE 14 Comparison of jet-wake and mixed-out velocity vectors (with data reduction mode using three-dimensional prediction results): (a) jet-wake model from Japikse, and (b) jet-wake model from Rohne.

Reasonable pre-input of the secondary mass and the area fractions in the two jet-wake models are critical for the accurate performance prediction. Figure 15 shows the effects of the parameters on the predicted values of total pressure and temperature. The dashed lines denote the total conditions at the impeller exit in the present calculations. The models can be investigated and improved using the CFD technique in the future. 
a)
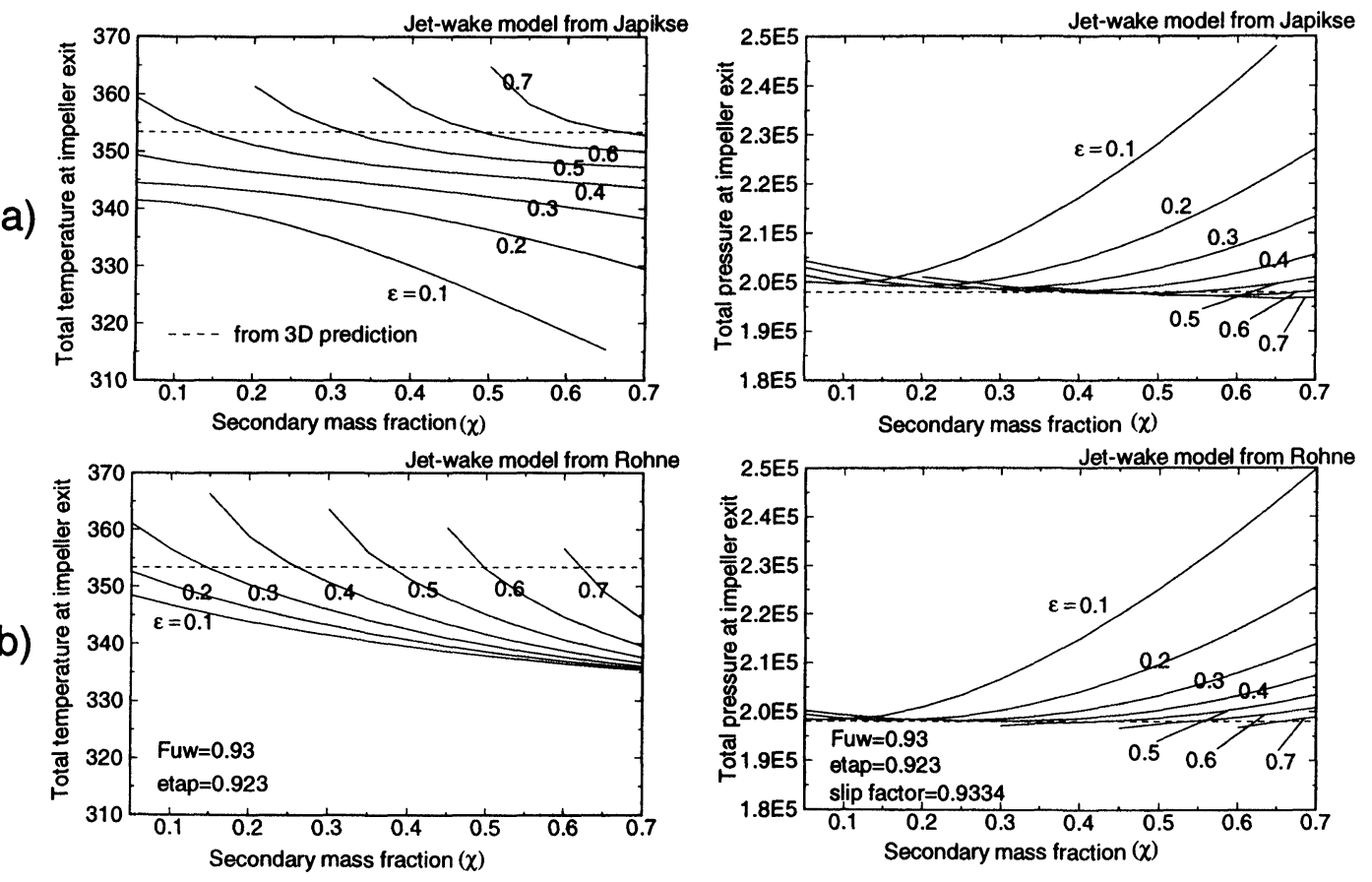

FIGURE 15 Variation of exit total conditions with wake mass and area fractions: (a) jet-wake model from Japikse, and (b) jet-wake model from Rohne.

\section{CONCLUSIONS}

(1) The present CFD code correctly predicts the pressure ratio, total temperature increase and efficiency of the centrifugal impeller over a wide range of operating condition from the near surge to choke flow rates.

(2) The predicted flow development through the impeller is in good agreement with the measured data.

(3) The code reasonably simulates the evolution of the secondary flow in the impeller which affects the jet-wake formation and location. The core of the wake region at the impeller exit exists near the suction side for the near stall flow rate, and the shroud/suction side corner for the design and near choke flow rates.

(4) The predicted values of slip factor increase with the flow rate for the backswept Eckardt impeller and are in good agreement with measured values.

(5) The distribution of entropy generation is strongly three-dimensional and correlated with the passage blockage.

(6) The mixed-out velocity vectors by the present three-dimensional flow prediction are in good agreement with the values from the two jetwake models except small differences in the calculated total conditions at the impeller exit. However, unusually large values of the mass fraction should be used in the two jet-wake models to match the calculated total temperature and pressure at the impeller exit.

\section{Acknowledgment}

The authors are indebted to Korea Science and Engineering Foundation through Turbo and Power Machinery Research Center for financial support. 


\section{NOMENCLATURE}

\begin{tabular}{|c|c|}
\hline$A$ & area \\
\hline$b$ & meridional channel width \\
\hline$c$ & absolute velocity \\
\hline \multicolumn{2}{|l|}{$C_{\mu}, C_{1}$} \\
\hline$C_{2}, \sigma_{k}, \sigma_{\varepsilon}$ & $\begin{array}{l}\text { constants in turbulence closure } \\
\text { models }\end{array}$ \\
\hline$F_{u \mathrm{w}}$ & $\begin{array}{l}\text { circumferential velocity factor for } \\
\text { wake }\end{array}$ \\
\hline$h$ & enthalpy \\
\hline$H_{\mathrm{R}}$ & rothalpy \\
\hline$k$ & turbulence kinetic energy \\
\hline$m$ & mass flow rate \\
\hline$p$ & pressure \\
\hline PS & pressure side \\
\hline$p^{*}$ & $\begin{array}{l}\text { rotary stagnation pressure } \\
\left(p+\frac{1}{2} \rho W^{2}-\frac{1}{2} \rho \omega^{2} r^{2}\right)\end{array}$ \\
\hline
\end{tabular}

$P^{*}$

$R$

$R_{0}$

$R_{n}$

$S_{\mathrm{m}}$

SS

$t$

T

$u$

$U_{2}$

$W$

$y / t$

$z / b$

$x / S_{\mathrm{m}}$

$x, y, z$

I, II, III,

IIIa, IV, V optical measuring planes

$\chi$

$\delta_{i j}$

$\varphi$ $\varepsilon \quad$ dissipation rate of turbulence energy or wake area fraction

$\mu \quad$ viscosity or slip factor

$\mu_{t} \quad$ eddy viscosity

$\xi, \eta, \zeta \quad$ general curvilinear coordinate system

$\rho \quad$ density

$\omega, \Omega \quad$ impeller rotational speed

\section{Superscripts}

, fluctuating component

\section{Subscripts}

I inlet

J jet

m meridional component or mixed-out condition

opt optimum condition

$u \quad$ tangential component

w wake

2 impeller exit

$\infty \quad$ ideal, blade-congruent flow

$0 \quad$ stagnation condition

\section{References}

Eckardt, D. (1980) Flow field analysis of radial and backswept centrifugal compressor impellers, Part 1: Flow measurements using a laser velocimeter, The 25th Annual International Gas Turbine Conference, New Oreans, Louisiana, March 9-13, $77-86$.

Farge, T.Z. and Johnson, M.W. (1992) Effect of flow rate on loss mechanisms in a backswept centrifugal impeller, Int. J. Heat and Fluid Flow, 13 (2), 189-195.

Hah, C., Bryans, A.C., Moussa, Z. and Tomsho, M.E. (1988) Application of viscous flow computations for the aerodynamic performance of a backswept impeller at various operating conditions, Journal of Turbomachinery, 110, 303-311.

Inoue, M. and Cumpsty, N.A. (1984) Experimental study of centrifugal impeller discharge flow in vaneless and vaned diffusers, Journal of Engineering for Gas Turbines and Power, 106, 455-467.

Japikse, D. (1985) Assessment of single and two-zone modeling of centrifugal compressors. Studies in component performance: Part 3, ASME Paper No. 85-GT-73.

Karki, K.C. and Patankar, S.V. (1988) Calculation procedure for viscous incompressible flows in complex geometries, Numerical Heat Transfer, 14, 295-307. 
Ramamurti, R., Ghia, U. and Ghia, K.N. (1988) Simulation of two-dimensional viscous flow through cascade using a semielliptic analysis and hybrid C-H grids, NASA CR 4180 .

Rohne, K.H. and Banzhaf, M. (1991) Investigation of the flow at the exit of an unshrouded centrifugal impeller and comparison with the "classical" jet-wake theory, Journal of Turbomachinery, 113, 654-659.

Schuster, P. and Schmidt-Eisenlohr, U. (1980) Flow field analysis of radial and backswept centrifugal compressor impellers, Part 2: Comparison of potential flow calculations and measurements, The 25th Annual International Gas Turbine Conference, New Oreans, Louisiana, March 9-13, 87-95.

Wiesner, F.J. (1967) A review of slip factors for centrifugal impellers, Journal of Fluids Engineering, 89, 558-572.

Zangeneh, M. (1993) Inviscid-viscous interaction method for 3D inverse design of centrifugal impellers, ASME Paper No. 93-GT-103. 


\section{ait \\ ENERGY MATERIALS}

M A N E Y publishing

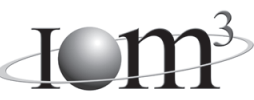

\section{Materials Science \& Engineering for Energy Systems}

Maney Publishing on behalf of the Institute of Materials, Minerals and Mining

The Institute of Materials, Minerals \& Mining

Economic and environmental factors are creating ever greater pressures for the efficient generation, transmission and use of energy. Materials developments are crucial to progress in all these areas: to innovation in design; to extending lifetime and maintenance intervals; and to successful operation in more demanding environments. Drawing together the broad community with interests in these areas, Energy Materials addresses materials needs in future energy generation, transmission, utilisation, conservation and storage. The journal covers thermal generation and gas turbines; renewable power (wind, wave, tidal, hydro, solar and geothermal); fuel cells (low and high temperature); materials issues relevant to biomass and biotechnology; nuclear power generation (fission and fusion); hydrogen generation and storage in the context of the 'hydrogen economy'; and the transmission and storage of the energy produced.

As well as publishing high-quality peer-reviewed research, Energy Materials promotes discussion of issues common to all sectors, through commissioned reviews and commentaries. The journal includes coverage of energy economics and policy, and broader social issues, since the political and legislative context influence research and investment decisions.

\section{CALL FOR PAPERS}

Contributions to the journal should be submitted online at http://ema.edmgr.com

To view the Notes for Contributors please visit: www.maney.co.uk/journals/notes/ema

Upon publication in 2006, this journal will be available via the Ingenta Connect journals service. To view free sample content online visit: www.ingentaconnect.com/content/maney

For further information please contact:

Maney Publishing UK

Tel: +44 (0)113 2497481 Fax: +44 (0)1132486983 Email: subscriptions@maney.co.uk

or

Maney Publishing North America

Tel (toll free): 8662975154 Fax: 6173546875 Email: maney@maneyusa.com

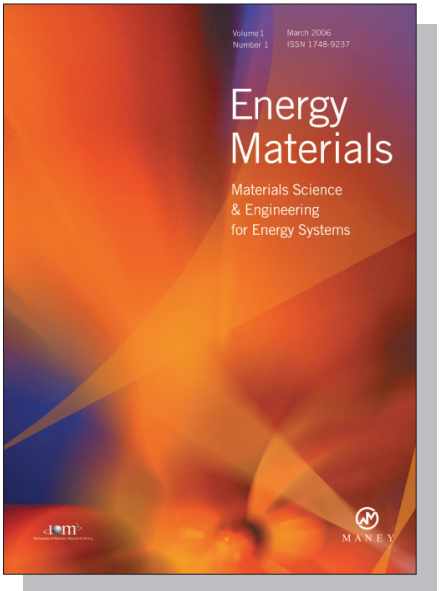

EDITORS

Dr Fujio Abe

NIMS, Japan

Dr John Hald, IPL-MPT, Technical University of Denmark, Denmark

Dr R Viswanathan, EPRI, USA

\section{SUBSCRIPTION INFORMATION}

Volume 1 (2006), 4 issues per year

Print ISSN: 1748-9237 Online ISSN: 1748-9245

Individual rate: $£ 76.00 / U S \$ 141.00$

Institutional rate: $£ 235.00 /$ US $\$ 435.00$

Online-only institutional rate: $£ 199.00 / U S \$ 367.00$

For special $\mathrm{IOM}^{3}$ member rates please email

subscriptions@maney.co.uk

\section{For further information or to subscribe online please visit www.maney.co.uk}



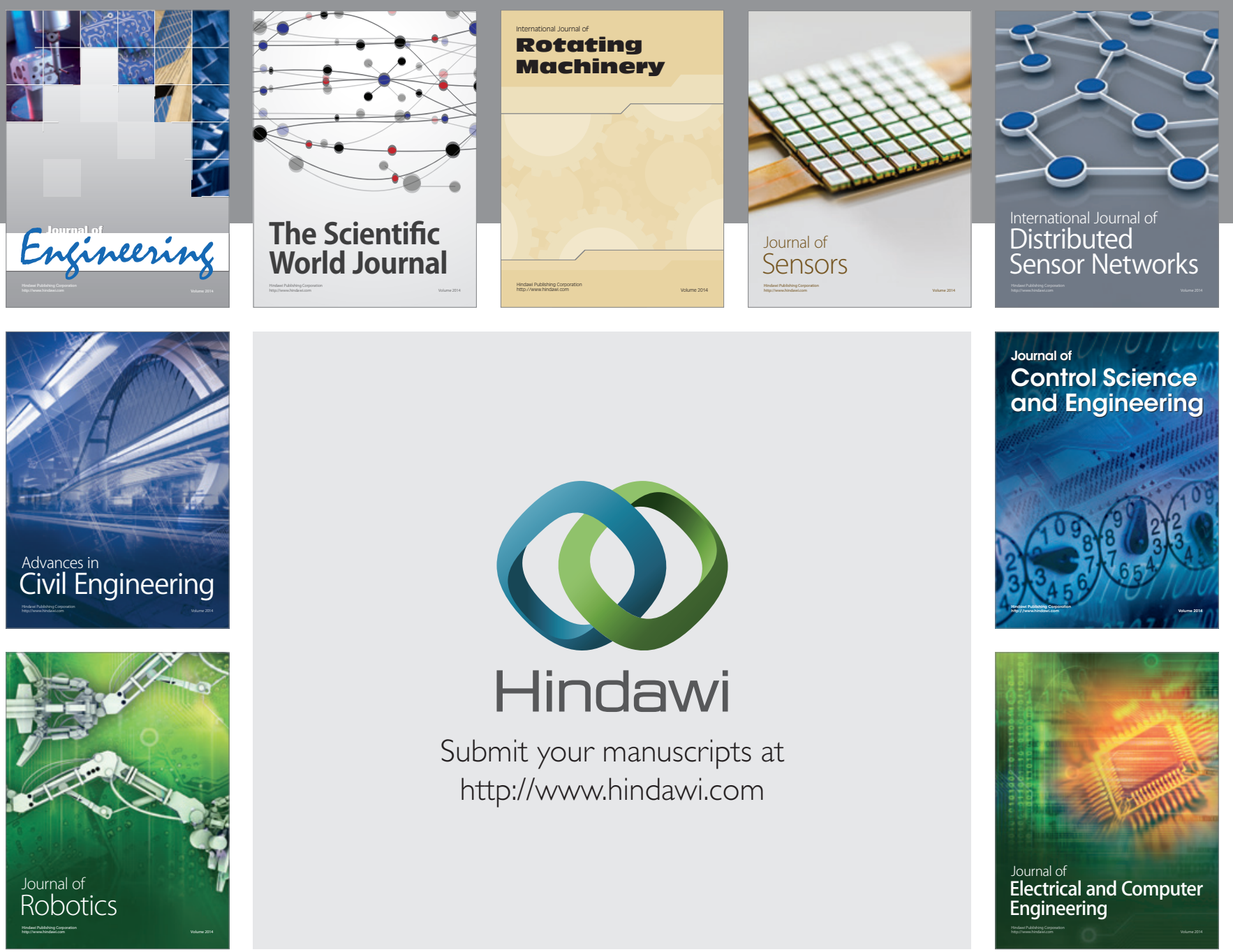

Submit your manuscripts at

http://www.hindawi.com
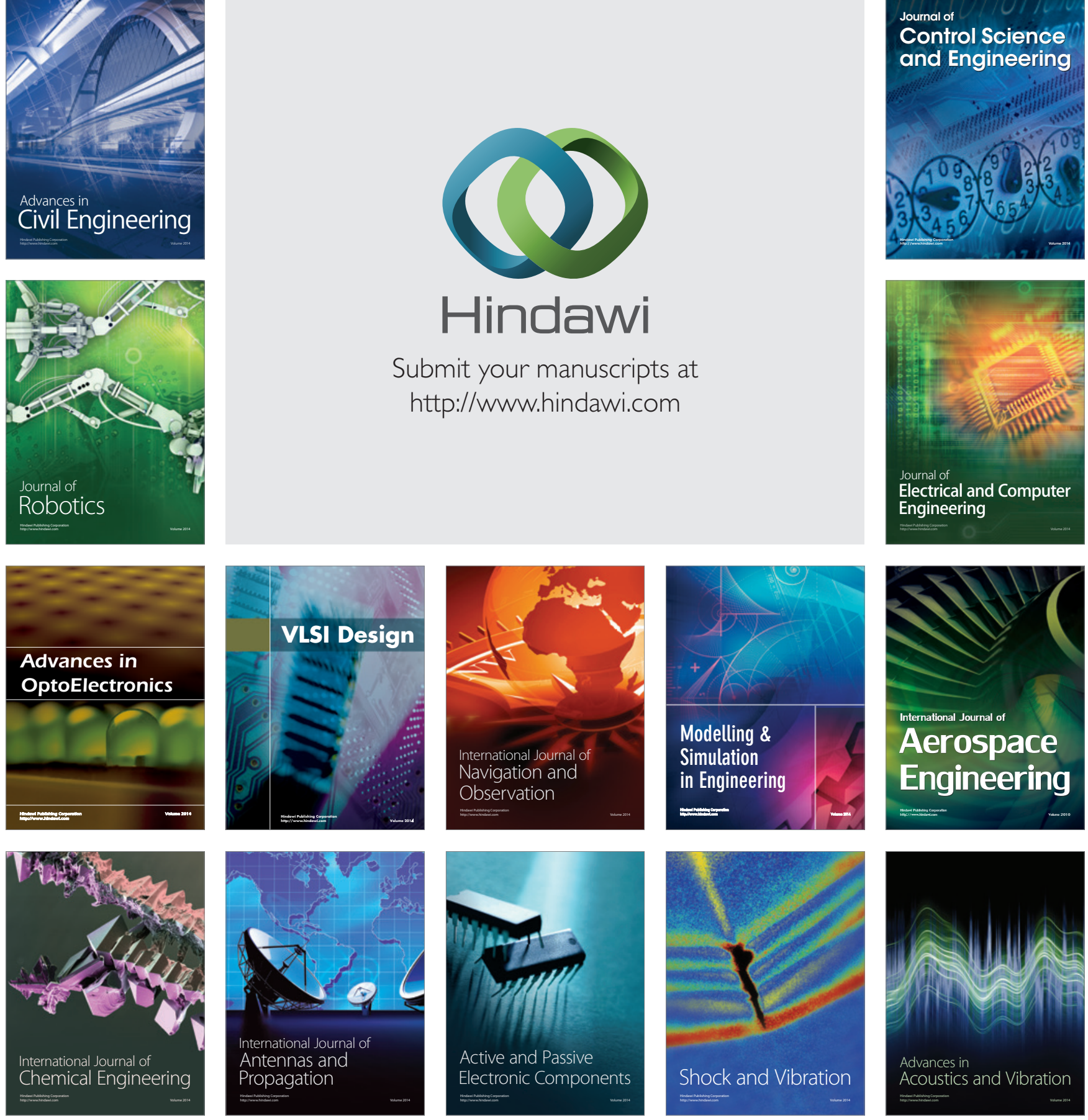